\title{
A SUBMISSÃO DA MULHER NEGRA E A VIOLÊNCIA DOMÉSTICA: UMA LEITURA DISCURSIVA DO CONTO ARAMIDES FLORENÇA, DE CONCEIÇÃO EVARISTO
}

Mara Rubia N. Costa Fanti

\section{Considerações iniciais}

A luxúria, ou seja, o desejo desordenado ou o prazer desregrado, sem estar ligado às finalidades de procriação e união, sempre foi objeto de condenação para as religiões cristãs. É, inclusive, um dos sete pecados capitais, segundo o Catecismo da Igreja Católica (2012). Trata-se de um pecado gravíssimo para os católicos porque infringe diretamente o Sexto Mandamento: Não pecar contra a castidade (Êxodo 20, 2-17). Os pecados relacionados a esse mandamento vão desde a masturbação e a homossexualidade até a busca 
pelo prazer em relações sexuais fora do casamento, o que constitui adultério.

A relação sexual somente é permitida e incentivada, sob essa perspectiva religiosa, dentro do matrimônio, o qual se configura como um antídoto contra a luxúria, uma vez que a libido, nessa condição, não é reprimida, pois contribui para gerar mais fiéis para os bancos da Igreja. Nesse sentido, é vetado à mulher o direito de se negar a praticar sexo com seu esposo, uma vez que a posição que ocupa no casamento é inferior à do homem. A religião católica, de base patriarcal, define o papel de submissão a que a mulher está destinada na relação conjugal a partir de uma interpretação do discurso teológico ( $\mathrm{Col} 3$-18): o homem é aquele a quem a mulher deve obediência.

O campo literário oferece bastantes discursos nos quais é possível refletir sobre como o discurso da religioso católico corrobora a condição inferiorizada da mulher no matrimônio. Ao lado do discurso religioso que inferioriza o papel da mulher, o racismo estrutural impossibilita que mulheres brancas e negras sejam tratadas de forma igualitária socialmente. $\mathrm{O}$ resultado disso é o fato de as mulheres negras continuarem sendo as maiores vítimas de violência doméstica, conforme os números de pesquisa realizada pelo Núcleo de Estudos da Violência da USP em 2020.

Apesar de o posicionamento machista constituir as bases de muitos discursos em circulação na sociedade brasileira, ele jamais é assumido, porém margeia o dizer e é corroborado por diversos discursos religiosos. Somado a isso, o racismo estrutural orienta condutas e discursos, os quais, apesar de refutados por uma parcela da sociedade, ainda fazem parte da memória discursiva de muitos. A mulher negra, nessas condições sócio-históricas, é duplamente inferiorizada: por ser mulher e negra. 
Nas Artes, a literatura brasileira canônica apresenta personagens negras que reforçam os estereótipos negativos que acompanham a cor de sua pele: como o da mulher sensual, cuja lascívia é capaz de macular a família tradicional portuguesa, representada pela personagem Rita Baiana ou o estereótipo da mulher animalizada, como Bertoleza, de $O$ cortiço (1890), que morre focinhando. Ou ainda o daquela que personifica a incapacidade de se submeter às convenções sociais e é dona de uma ingênua conduta marcadamente sexual como a protagonista de Gabriela, cravo e canela (1958). Tais estereótipos sustentam a memória coletiva que reatualiza posicionamentos do período colonial, conforme orienta $\mathrm{Du}$ arte (2010, p. 24):

Branca para casar, preta para trabalhar e mulata para fornicar": assim a doxa patriarcal herdada dos tempos coloniais inscreve a figura da mulher presente no imaginário masculino brasileiro e a repassa à fiçça e à poesia de inúmeros autores.

As personagens literárias alimentam o imaginário coletivo e traduzem o posicionamento de que a mulher negra é a personificação do sexo descompromissado, uma vez que sua representação está ligada à sensualidade, à promiscuidade e à satisfação dos desejos masculinos, como explica Duarte (2013, p.146)

Ainda quanto às figurações do feminino, nas mulheres o protagonismo ocorre com mais frequência, desde o romantismo, bastando lembrar Vítimas-algozes, de Joaquim Manuel de Macedo, entre outros. É, entretanto, um protagonismo marcado, em muitos casos, pela permanência, na ante cena textual, do mesmo projeto de 
desumanização que subjaz à estereotipia. Ele se manifesta em construções que ressaltam, por exemplo, a sensualidade e a disponibilidade para o sexo sem compromissos ou consequências, novamente de acordo com as imagens sociais a priori, como a da "mulata assanhada" entre outras.

O estereótipo não permite o florescimento de uma outra identidade para a mulher negra porque a relega a uma face unívo$\mathrm{ca}$, atuando, assim como uma forma de aprisionamento cultural e social de sua imagem. Tal fato determina o perfil dessas personagens no campo literário e alimenta a memória discursiva da sociedade brasileira de discursos preconceituosos e sexistas que remontam as relações sociais do período da escravidão.

A Literatura Negra, ou Afro-brasileira como optamos por chamar em consonância com Evaristo (2009), torna-se um campo em que o negro assume o protagonismo sobre o ato de falar de si e escancara as mazelas de um povo que historicamente foi silenciado, apagado, esquecido por tentativas de embranquecimento da população e da cultura nacionais.

Nesse espaço, a mulher negra, duplamente inferiorizada, assume a voz para contar sua verdadeira história, quebrar estereótipos e romper os grilhões do silêncio.

Em síntese, quando escrevo, quando invento, quando crio a minha fiç̧ão, não me desvencilho de um "corpo-mulher-negra em vivência" e que por ser esse "o meu corpo, e não outro", vivi e vivo experiências que um corpo não negro, não mulher, jamais experimenta. As experiências dos homens negros se assemelham muito 
às minhas, em muitas situações estão par a par, porém há um instante profundo, perceptível só para nós, negras e mulheres, para o qual nossos companheiros (Evaristo, 2009, p. 18)

Apenas as mulheres negras podem enunciar as próprias experiências e denunciar o quanto as relações sociais são contaminadas por questões étnico-raciais que desvelam o preconceito e a violência a que estão submetidas porque esse é um lugar de fala pertencente a elas. Assim, no discurso literário produzido por enunciadores que se revelam mulheres e negras, ficção e realidade interpelam-se no dizer e revelam uma visão singular de uma realidade marcada pelo racismo estrutural e o machismo não assumido.

O capítulo tem como tema as relações de poder no matrimônio, a violência sexual e a dominação masculina sobre o corpo da mulher negra colocada em foco na encenação literária, considerando as imposições histórico-culturais materializadas linguisticamente na enunciação. Partimos do princípio de que estudar essa temática em textos representativos da Literatura Afro-Brasileira contribui para as discussões acerca do machismo, do lugar de fala da mulher negra e a linguagem como instauração da submissão/ apagamento dessa mulher em nossa sociedade.

Para dar conta de nossa proposta, escolhemos o conto Aramides Florença, da obra Insubmissas Lágrimas das Mulheres (2016), de autoria de Conceição Evaristo, o qual problematiza determinadas posições da mulher negra a partir de uma voz feminina. Evaristo, umas das mais produtivas escritoras negras da atualidade, cria um sujeito enunciativo que expõe as condições de vida da mulher negra e as forças sociais que promovem e garantem a manutenção da subalternidade feminina e da violência. 
Para procedermos à análise, fundamentamo-nos no quadro da Análise do Discurso (AD), de linha francesa, cujo aparato metodológico se apoia na linguagem como evento discursivo. Para a AD, o evento linguístico que coloca a língua em funcionamento é fruto de um processo histórico e social que permite relacionar a organização dos textos aos lugares nos quais são produzidos.

Ao assumirmos a $\mathrm{AD}$ para dar conta de nossos objetivos, podemos articular a posição-sujeito ao posicionamento crítico que visamos neste artigo. As perspectivas enunciativo-discursivas propostas por Maingueneau (2018) relacionam o discurso a um sujeito que atua ao mesmo tempo como fonte de referências pessoais, temporais e espaciais e permite a negociação de efeitos de sentido.

Por seu caráter interdisciplinar, a $\mathrm{AD}$ permite um diálogo entre a Linguística, a Literatura e a Religião o qual possibilita uma quebra de oposição entre os campos do conhecimento que se aproximam por meio da discursividade, uma vez que Maingueneau (2018) entende a enunciação literária como um evento discursivo. As condições do dizer permeiam aí o dito, e o dito remete a suas próprias condições de enunciação (p.43).

Para dialogar com a $\mathrm{AD}$, na perspectiva de Maingueneau, com relação à condição das mulheres negras, a Literatura Afro-brasileira e a negritude, buscamos autores que abordam a questão do negro, o racismo e a relação com a mulher negra. Esses autores enxergam a linguagem como um campo de disputas, no qual a Literatura assume papel de destaque por constituir um espaço no qual autoras e autores negros assumem seu lugar de fala em prol de uma sociedade verdadeiramente inclusiva.

Entre eles estão Bernd (1988), Evaristo (2009), Cuti (2010), Assis (2013, 2014), Ribeiro (2017), e Almeida (2021), cujos estudos 
ampliam a discussão acerca do negro, da Literatura Afro-Brasileira e o lugar ocupado pela mulher negra na literatura e na sociedade de modo a garantir o respeito aos direitos e às raízes africanas que constituem sua identidade.

\section{A Escrevivência como projeto literário e as condições sócio-históricas de produção do discurso Aramides Florença}

Maria Conceição Evaristo de Brito, nascida em 1946 e criada em uma favela de Belo Horizonte, poderia ser mais uma Maria entre tantas, ocupando posições subalternas, marginalizadas socialmente. A autora modificou esse destino e buscou, por meio da escrita, promover o povo negro, a ancestralidade africana e deu voz à mulher negra, silenciada e oprimida. Ganhadora do Prêmio Jabuti, em 2015, pela obra Olhos d’água, do mesmo ano, Evaristo aparece no cenário literário nacional como uma das escritoras mais produtivas e reconhecidas da Literatura Afro-Brasileira.

Ela contesta, desde a mais tenra idade, a cor que lhe é atribuída e revela pela escrita que se saber negra implica muito mais que o reconhecimento da cor da pele, mas passa por uma consciência de negritude que está aliada à sua condição de classe. Essa conscientização liga-se a uma das características fundamentais do Movimento Negro contemporâneo que se baseia na construção de uma identidade positivada, com sentido político, capaz de fazer frente ao racismo estrutural e institucional.

Pela Escrevivência, conceito cunhado por ela mesma, em 1994, Evaristo relaciona o ato de escrever às vivências que perpassam a 
vida de negros e negras designados a um espaço de marginalidade social. Moradores da favela, desempregados, marginais, empregadas domésticas, prostitutas, trabalhadores da construção civil, nos textos de Evaristo, revelam as tensões existentes entre negros e brancos, ainda que do mesmo estrato social e discutem os conflitos que mobilizam as categorias de classe social, gênero e raça.

Ao desvelar os meandros do racismo, do silenciamento e apagamento a que o povo negro foi submetido historicamente, bem como as situações de violência motivadas por questões étnico-raciais, Evaristo constitui as bases de sua Escrevivência. Ao dar voz às experiências vividas por negras e negros, Evaristo permite que a mulher negra assuma o protagonismo sobre o seu dizer e sua história de modo a se construir discursivamente e quebrar o monopólio e a hegemonia de autores e críticos brancos na Literatura Brasileira.

Evaristo destaca o caráter militante da Escrevivência, a qual não se limita apenas a contar a história do povo negro, mas denunciar a dominação masculina sobre os corpos das mulheres negras:

Falar e ouvir entre nós era talvez a única defesa, o único remédio que possuíamos. Venho de uma família em que as mulheres, mesmo não estando totalmente livres de uma dominação machista, primeira a dos patrões, depois a dos homens seus familiares, raramente se permitiam fragilizar. Como "cabeça" da família, elas construíam um mundo próprio, muitas vezes, distantes $e$ independentes de seus homens e, mormente, para apoiá-los depois. Talvez por isso tantas personagens femininas em minhas narrativas? Pergunto sobre isto, não afirmo. (...) 
A nossa escrevivência não pode ser lida como histórias para "ninar os da casa-grande", e sim para incomodá-los em seus sonos injustos. (p. 20-21).

Ao falar do lugar de mulher e negra, Evaristo rompe com o processo de desumanização de toda uma população negra e transgride o discurso da branquitude, responsável por criar representações distorcidas de um povo retratado sempre como o Outro, de forma estereotipada e preconceituosa.

Sua enunciação empodera aqueles que sempre foram silenciados, apagados historicamente por um racismo estrutural e institucional que, embora negado, permeia as relações e legitima discursos, conforme Ribeiro (2020).

A escritora, avessa ao cânone literário, nega as influências europeias que dominam nossa cultura estético-literária. Contribui, dessa forma, para a consolidação da Literatura Afro-Brasileira por meio da apresentação de mulheres negras e enriquece a narrativa do eu por meio da escrita. Revela ainda a sua ancestralidade e valoriza a população negra em um país que caminha a passos lentos em direção ao pagamento da dívida histórica com os descendentes dos escravos africanos.

O discurso Aramides Florença opõe o impulso sexual, fruto da luxúria que resulta em violência e estupro, ao caráter sagrado da relação carnal, preconizado pelo discurso religioso, constituindo um tabu. O estupro, na relação conjugal, é pouco discutido e denunciado porque muitas mulheres atêm-se a uma crença obsoleta de débito matrimonial, ou seja, acreditam que tem o dever de praticar sexo no casamento. Tal crença, fruto do discurso religioso, revela a inferioridade do gênero feminino e a submissão de seu corpo. 
O Brasil é um país que se declara majoritariamente católico, segundo pesquisa Datafolha publicada em 2020. Tal posicionamento religioso, aliado a uma leitura da Bíblia que desconsidera o fato de que o sentido é algo dinâmico, ligado às condições sócio-históricas de produção, corrobora o caráter dominante do gênero masculino, dando-lhe plenos poderes sobre suas mulheres.

Apesar de ter sido banida do Código Penal Brasileiro, até 2005, existia a possibilidade de um estuprador não ser punido caso se casasse com a vítima. Percebe-se, desse modo, que ainda há uma grande dificuldade para a sociedade brasileira em reconhecer as relações sexuais não consentidas, dentro do casamento, como estupro.

\section{Bases teórico-metodológicas para a análise}

A base teórico-metodológica que fundamenta esse artigo é a Análise do Discurso de linha francesa $(\mathrm{AD})$ por consideramos que oferece categorias bastante produtivas para nosso estudo. A AD corrobora os postulados de Austin (1962) e Searle (1969), ao tomar o discurso como uma forma de ação sobre o outro, ou seja, toda enunciação constitui um ato (prometer, sugerir, afirmar, perguntar...) que visa modificar uma situação (Maingueneau, 2015, p. 25). No processo de interação, os efeitos de sentido vão sendo construídos a partir das condições sócio-históricas de produção.

$\mathrm{A} \mathrm{AD}$ não é uma disciplina hermenêutica, nesse sentido, não visa determinar um sentido único a um discurso, mas revela efeitos de sentido que são construídos e reconstruídos no interior das práticas sociais. Trata-se de uma disciplina que nasce interdisciplinar, desse modo, permite o diálogo entre a Linguística e a Literatura através da discursividade, conforme orienta Maingueneau: 
A partir do momento em que não se podem separar a instituição literária e a enunciação que configura um mundo, o discurso não se encerra na interioridade de uma intenção, sendo em vez disso força de consolidação, vetor de posicionamento, construção progressiva, através do intertexto, de certa legitimidade enunciativa e de um movimento de legitimação do espaço próprio espaço de sua enunciação. (MAINGUENEAU, 2018, p.43)

$\mathrm{O}$ analista francês defende que o texto literário não deve ser encarado como algo estanque, dependente exclusivamente de uma instância criadora. Essa perspectiva de estudos, centralizada no autor, adotada a partir do século XIX até os anos de 1960 do século XX, não considerava as condições do dizer que atravessam o dito, responsáveis por investir as próprias condições de enunciação. Nessas condições, estão implicados o gênero, o posicionamento, a relação com o destinatário por meio do texto, os suportes e o modo como os enunciados circulam, entre outras categorias discursivas.

Maingueneau entende o texto literário como um evento discursivo, no qual é possível analisar elementos da enunciação que não eram contemplados na perspectiva romântica dos estudos da Literatura. Assim, ao tomar o texto literário como discurso, o analista debruça-se sobre um estatuto pragmático particular, cuja existência é indiscutível na sociedade e permite o agrupamento de um conjunto considerável de textos pertencentes às épocas e sociedades diversas.

O discurso literário não constitui uma unidade delimitável e estável, conforme orienta o estudioso: 
A obra se enuncia através de uma situação que não é um quadro preestabelecido e fixo: ela pressupõe uma cena de fala determinada que precisa validar por meio de seu próprio enunciado. Ela se legitima através de um circuito: mediante o mundo que instaura, ela precisa justificar tacitamente a cena de enunciação que impõe desde o começo. (MAINGUENEAU, 2018, p. 55)

$\mathrm{Na}$ perspectiva da $\mathrm{AD}$, o discurso literário não é encarado como um discurso isolado apesar de sua especificidade, pois participa de um plano determinado de produção verbal que é o dos discursos constituintes. Esses discursos se propõem como discursos de Origem, os quais são validados por uma cena de enunciação que autoriza a si mesma. São discursos que fundam outros discursos e constituem uma categoria discursiva propriamente dita.

O discurso literário está associado ao trabalho de fundação no e pelo discurso, vincula-se a um grupo de locutores consagrados e são responsáveis pela elaboração de uma memória. Por ser um discurso constituinte, dá sentido aos atos da coletividade e funciona como garante de uma multiplicidade de gêneros do discurso.

Trata-se de um discurso paratópico, ou seja, quem enuncia nesse tipo de discurso não ocupa um lugar, nem fora nem dentro da sociedade, mas um lugar problemático (MAINGUENEAU, 2005). Essa condição mostra a impossibilidade de se atribuir, no discurso literário, assim como nos outros discursos constituintes, um lugar ao enunciador, mas apenas negociar um lugar e um não-lugar.

O autor do discurso literário é aquele que ocupa, no campo da Literatura e na sociedade, um lugar paradoxal, indissociável do processo de criação. De fato, a paratopia é uma condição da ativi- 
dade de escrita literária e essa categoria abre novas perspectivas de estudo na medida em que ela não se confunde com marginalidade, nomadismo ou parasitismo. Maingueneau (2005, p. 26) orienta:

\begin{abstract}
(...) a paratopia é ao mesmo tempo aquilo do qual é preciso se liberar pela criação e que a criação aprofunda, ela é ao mesmo tempo aquilo que dá possibilidade de ter acesso a um lugar (literário, utópico) e aquilo que proíbe todo o pertencimento.
\end{abstract}

Por meio da cena de enunciação, é possível apreender como se dá a construção de uma rede de efeitos de sentidos no discurso literário. Tal cena não pode ser confundida com a situação de comunicação. Ela é apreendida no interior do enunciado e possibilitada pela referenciação fornecida pelos dêiticos, os quais são responsáveis pela construção espaço-temporal e pessoal, legitimado pelos enunciados, conforme Maingueneau (2006).

Assim, o estudo de um determinado discurso não se restringe ao do enunciado, mas de todos os componentes que compõem a cena de enunciação, uma vez que se pauta no processo "do interior" que a situação de fala pretende definir, o momento em que a fala é encenada. Essa cena de enunciação é composta por três cenas: "cena englobante", "cena genérica" e "cenografia".

É por meio da cenografia que o co-enunciador interage com o discurso, uma vez que ela permite a construção de uma cena de fala a qual o discurso pressupõe para ser enunciado e que valida a própria enunciação. É aquilo de onde vem o discurso e aquilo que o discurso engendra. 
Trata-se da dimensão mais criativa do discurso, na qual se projeta o simulacro de um momento, de um espaço e dos papéis sociais conhecidos e partilhados socialmente. É construída com cenas validadas, isto é, com cenas de fala que se instalaram na memória coletiva seja por meio de modelos que se rejeitam ou se valorizam, conforme Maingueneau (2002).

\section{Análise do discurso Aramides Florença}

Para nosso estudo, escolhemos o discurso Aramides Florença, da obra Insubmissas lágrimas das mulheres (2016). Primeiro livro de contos de Conceição Evaristo, a obra é constituída por 13 contos, nos quais vozes de mulheres negras, a partir de um trabalho de reconstrução da memória individual, narram suas histórias a uma personagem que é, ao mesmo tempo, interlocutora das protagonistas e contadora dessas histórias.

Esse enunciador que se revela do gênero feminino ora se oferece à escuta, ora registra os discursos. Eles versam sobre experiências pessoais de superação do sofrimento que as mulheres experenciaram no passado, cujo caráter resiliente serve de fio condutor para os relatos.

Justificamos a nossa opção pelo discurso literário Aramides Florença pelo fato de ele desvelar as posições de submissão, violência e silenciamento impostas à mulher negra e motivar uma reflexão acerca da inferiorização dessa mulher nas relações sociais.

Objetificada pelo homem branco que a destitui de humanidade, a mulher negra segue invisível nos debates políticos e acadêmicos, tendo pouco ou nenhum alcance às políticas públicas que garantam a satisfação de suas necessidades e direitos como cidadã. 
Ela deve permanecer militando pelo direito de existir e poder dizer.

Ao examinarmos o discurso Aramides Florença produzido por Evaristo, verificamos a cena genérica de um conto, que se constrói a partir da cenografia de um encontro entre duas mulheres. $\mathrm{O}$ enunciador que ora se coloca como ouvinte, ora como quem registra o discurso a fim de compartilhar com seu co-enunciador, coloca em cena a mulher negra.

Esposa e mãe, essa mulher da enunciação literária contraria o estereótipo da mulher negra estéril, que desfruta o prazer sexual de forma descompromissada, fora dos laços de matrimônio que é construído na literatura canônica, conforme Assis Duarte (2010, p. 24):

(...) Via de regra, desgarrada da família, sem pai nem mãe, e destinada ao prazer isento de compromissos, a mulata construída pela literatura brasileira tem sua configuração marcada pelo signo da mulier fornicaria $d a$ tradição europeia, ser noturno e carnal, avatar da meretriz. Chama a atenção, em especial, o fato dessa representação, tão centrada no corpo de pele escura esculpido em cada detalhe para o prazer carnal, deixar visivel em muitas de suas edições um sutil aleijão biológico: $a$ infertilidade que, de modo sub-reptício, implica em abalar a própria ideia de afrodescendência.

Por meio de um regime misto, autora e enunciador sobrepõem seus enunciados a fim de apresentar Aramides como o referente da representação discursiva inserida em um contexto histórico e social. Essa cena, construída pelo discurso, desvela as forças so- 
ciais que submetem a mulher negra e como os estereótipos que compõem a memória coletiva interferem no tratamento dado a ela. Isso reflete nas condutas daqueles com os quais ela se relaciona. Iniciaremos nossa análise pelo título que se revela como uma estratégia de ativação de efeitos de sentidos, partindo da memória discursiva acionada a partir do interdiscurso.

Para iniciarmos nossa reflexão, tomaremos o nome próprio que dá título ao discurso: Aramides Florença. Aramides Cajaneus é o nome científico do pássaro Saracura, cuja característica marcante é ficar escondida durante o dia e cantar somente três vezes: ao amanhecer e ao anoitecer ou para anunciar uma chuva forte.

O sujeito, construído na enunciação, pouco ou nada diz. Assim, o discurso literário é atravessado pelo discurso da Biologia de modo a ressaltar a similaridade entre o comportamento do sujeito construído no interior do discurso e o da ave.

Aramides Florença, como a ave, passa os dias silenciosa. A personagem não reage às agressões veladas que sofre do marido durante a gravidez. Somente após o estupro, assume a própria voz para denunciar a violência sofrida por meio de uma enunciação, cuja força é garantida pelo seu lugar de fala: o de mulher que se irmana a tantas outras que tiveram o corpo violado sexualmente.

Nesse sentido, Aramides não é um código linguageiro aleatório, pois carrega pistas acerca do comportamento do sujeito as quais devem ser perseguidas no processo de compreensão do discurso. Aramides Florença é um sujeito de referência discursiva, pois nos remete à sua situação social e desvela a condição psicológica não apenas de uma personagem, mas de toda uma coletividade feminina e negra: a do silêncio perante a violência doméstica. 
O título Aramides Florença permite uma existência real, não somente ficcional à medida que a recordação de suas características fundamenta sua identidade. O interdiscurso da Biologia incorpora ao discurso literário a imagem da mulher silenciosa que não se permite o direito à voz e que se submete, sem questionamentos, à violência na relação conjugal.

A cenografia encena o encontro do enunciador com Aramides Florença o qual se deu com o intuito de colher o relato, por meio da escuta, para registrá-lo com o objetivo de o compartilhar com os co-enunciadores. $\mathrm{O}$ enunciador insere Aramides na cenografia, utilizando mecanismos descritivos-literários a partir de um discurso realista, a fim de retratar uma cena que faz parte da memória discursiva dos co-enunciadores.

Aramides representa o estereótipo da mulher e mãe, cuja ocupação principal é cuidar do filho, ainda que sozinha. Para dar a impressão de verossimilhança ao co-enunciador, o enunciador recorre a uma descrição minuciosa das ações de mãe e filho.

Para nós, a mistura entre realidade e ficção ocorre com o objetivo de garantir o estatuto estético-literário proposto por Evaristo. As ações de Aramides inserem-na no contexto social de marginalização da mulher negra e que, no discurso em análise, é somado ao silenciamento e abandono das vítimas de violência doméstica.

Na construção da cenografia, o discurso literário é atravessado pelo religioso, pois a descrição, feita pelo enunciador, da imagem de Aramides e seu filho, remete à imagem católica da Santa Virgem Maria com o Menino Jesus. O enunciador revela que, ao ver Aramides com seu filho nos braços, perdeu-se em contemplação, conduta assumida por fiéis diante da imagem dos santos. 
Ao tomar essa imagem que faz parte da memória discursiva, desvela-se o posicionamento de que a maternidade assume uma dimensão sagrada, conforme o recorte a seguir:

Quando cheguei à casa de Aramides Florença, a minha igual estava assentada em uma pequena cadeira de balanço e trazia, no colo, um bebê que tinha a aparência de quase um ano.

Esta é minha criança - me disse a mãe, antes de qualquer outra palavra- o meu bem-amado. O nome dele é Emildes Florença.

E susteve a criança em minha direção, como se fosse me oferecer um presente. O menininho sorriu para mim, percebi que alguns dentinhos enfeitavam sua pequenina boca e reconheci no gesto dele um aceno de boas vindas. Por uns momentos me esqueci da mãe e me perdi na contemplação do filho. (p.9)

O último enunciado do recorte em análise, porém, confronta essa sacralidade que parece colocar em destaque o sujeito feminino na enunciação. $\mathrm{O}$ menino, nos braços da mãe, faz com que a mulher seja momentaneamente esquecida pelo enunciador. Tal fato desnuda o posicionamento, presente na memória discursiva da sociedade brasileira, de que a mulher, ao tornar-se mãe, deve anular-se, colocar-se em segundo plano a fim de satisfazer todas as necessidades de sua prole, sejam elas de afeto ou alimento. 
Percebe-se claramente o confronto entre os dois sujeitos masculinos pelo corpo de Aramides: o filho que se alimentava exclusivamente do leite materno e o pai que ansiava pelo corpo da mulher a fim de satisfazer seus desejos sexuais. Aramides, apesar de ser o centro da enunciação, não toma a palavra.

Tal qual outros discursos literários produzidos por Evaristo, as vozes de enunciador e autor misturam-se de modo a unir o plano da ficção ao da realidade, no intuito de revelar o cotidiano de opressão imposto às mulheres negras. Mulheres subjugadas duplamente: por seu gênero e por serem negras.

Aramides não toma a palavra, apenas o enunciador descreve os sujeitos que compõem a cena. Ao ser abandonada pelo esposo, o filho vence o confronto e pode ter a mãe somente para si, conforme pode ser observado no recorte a seguir:

Aramides Florença buscava ser o alimento do filho. E, literalmente, era. O menino só se nutria do leite materno. A sopinha que o pediatra preparava cuidadosamente, o bebê provava, recusando sempre. Ela, pacientemente, insistia, cantava, dançava, sorria. Ele também fazia festas à festa da mãe. Mas quanto ao aceite da comidinha, nada. (...) E o jogo que o filho fazia, emparelhado ao dela, era mais sedutor. A vitória sempre pertencia ao pequeno. Entretanto, nem sempre fora assim, antes havia a figura do pai por perto. (p.10)

$\mathrm{O}$ atravessamento do discurso religioso por meio de imagens e do código linguageiro acionam efeitos de sentido que (re)constroem posicionamentos arraigados na memória coletiva. Esses posicionamentos aproximam a maternidade do caráter divino, do 
milagre, no qual o homem é apenas um coadjuvante, conforme o recorte 3 : O pai, embevecido e encabulado com o milagre que também fazia acontecer, repartia os seus mil sorrisos ao lado da mãe. (p. 12)

Aramides, após se tornar mãe, transforma-se em um ser inacessível, por esse motivo, objeto de disputa entre pai e filho, ressignificando a tragédia grega de Édipo e Jocasta, na qual o filho mata o pai e tem como prêmio a mãe. O bebê, obviamente, não tem consciência da disputa que trava com o outro sujeito masculino. Essa disputa orienta a conduta do ex-companheiro de Aramides, o qual tomado pelo ciúme, imprime à esposa pequenos gestos de violência durante à gravidez que culminaram no estupro da mulher após o nascimento da criança, conforme o recorte 4 :

Um dia algo dolorido no ventre de Aramides inaugurou uma perturbação entre os dois. Já estavam deitados, ela virava para lá e para cá, procurando uma melhor posição para encaixar a barriga e, no lugar em que se deitou, seus dedos esbarraram em algo estranho. Lá estava um desses aparelhos de barbear, em que se acopla a lâmina na hora do uso. Com dificuldade para se erguer, gritou de dor. Um filete de sangue escorria de um dos lados de seu ventre. Aramides não conseguiu entender a presença daquele objeto estranho em cima da cama. Havia dias que o barbeador elétrico de seu companheiro havia estragado e ele estava usando um daqueles antigos. $O$ homem, pai do filho de Aramides Florença, não soube explicar a presença do objeto ali. (p. 13) 
O discurso religioso católico atravessa o literário a fim de instaurar a aura de inacessibilidade e sacralidade à mulher que se torna mãe, posicionamento que faz parte da memória coletiva a qual se alimenta também desse discurso, o que aproxima todas as mães de Maria, mãe de Jesus e os outros componentes da Sagrada Família, conforme o recorte 5: Mãe, pai e filho felizes no outro dia, deixaram o hospital. Sagrada a família! - o homem repetia cheio de júbilos a louvação de sua trindade: ele, a mulher e o filho. (p.15)

Faz-se um jogo de contraste entre ação e aparência, pois aquilo que o pai diz tem apenas a aparência de verdade, são nas ações que o sujeito revela a violência e o ciúme. $\mathrm{O}$ enunciador segue o discurso em terceira pessoa. Aramides, centro da enunciação, não toma a palavra, apaga-se, silencia-se, perde a própria humanidade, pois se transforma em objeto de posse, cuja função é o prazer sexual do marido, conforme o recorte 6 :

Passadas as duas primeiras semanas, uma noite, já deitados, o homem olhando para o filho no berço, perguntou a Aramides, quando ela seria dele, só dele. A indagação lhe pareceu tão despropositada, que ela não conseguiu responder, embora tenha percebido o tom ciumento da pergunta. (p.15)

Na construção da cenografia do estupro, o enunciador silencia-se e Aramides assume a voz no relato do ato de violência cometido pelo esposo contra si. Ela fala, pois é sobre si que recai diretamente a violência e o abandono impostos pela sua condição e gênero.

Toda a aura de sacralidade, instaurada pelo atravessamento do discurso religioso, é descontruída, maculada pela sequência des- 
critiva dos atos violentos que culminam no estupro e abandono de Aramides. As ameaças veladas, subentendidas ou silenciadas, tomaram corpo concreto, a coisificação da mulher é revelada: ela é apenas objeto de posse, de satisfação dos desejos masculinos.

$\mathrm{O}$ ato de estupro macula a cena da amamentação do filho, o qual, tomado como um sujeito adversário, é afastado violentamente, ameaçado pelo pai que coloca o bebê, sem nenhum cuidado, no bercinho, contendo o impulso de matar a criança, último ato que o afasta da bestialidade.

Aramides representa, no ato enunciativo, todas as mulheres que sofrem violência doméstica: solitária e indefesa diante do agressor que tem direito sobre seu corpo porque a comunidade discursiva o legitima. $\mathrm{O}$ ato violento representa a quebra do contrato, do pacto selado no matrimônio, o qual deixa de gerar vida para simbolizar a anulação total da vontade e do poder feminino sobre o próprio corpo, conforme o recorte 7 :

Estava eu amamentando o meu filho - me disse Aramides enfatizando o sentido da frase, ao pronunciar pausadamente cada palavra - quando o pai de Emildes chegou. De chofre arrancou o menino de meus braços, colocando-o no bercinho sem nenhum cuidado. Só faltou arremessar a criança. Tive a impressão de que tinha sido esse o desejo dele. No mesmo instante, eu já estava de pé agarrando-o pelas costas e gritando desesperadamente. Ninguém por certo para socorrer o meu filho e a mim. Numa sucessão de gestos violentos, ele me jogou sobre a nossa cama, rasgando minhas roupas e tocando violentamente com a boca um de meus seios que estava descoberto, no ato de amamentação de meu filho. E, dessa forma, o pai 
de Emildes me violentou. E, em mim, o que ainda doía um pouco pela passagem de meu filho, de dor aprofundada sofri, sentindo o sangue jorrar. Do outro seio, o que ele não havia tocado, pois defensivamente eu conseguira cobrir com o lençol, eu sentia o leite irromper. Nunca a boca de um homem, como todo seu corpo, me causara tanta dor e tanto asco, até então. E, inexplicavelmente, esse era o homem. Aquele que eu tinha escolhido para ser meu e com quem eu havia compartilhado sonhos, desejos, segredos prazeres. E, mais que isso, havia deixado conceber em mim, um filho. Era esse homem que me violentava, que machucava meu corpo e a minha pessoa, no que eu tinha de mais íntimo. Esse homem estava me fazendo coisa dele, sem se importar com nada, nem com nosso filho, que chorava no berço ao lado.

E quando ele se levantou com seu membro murcho e satisfeito, a escorrer o sangue que jorrava de mim, ainda murmurou entre os dentes que não me queria mais, pois eu não havia sido dele, como sempre fora nos outros momentos de prazer. $($ p. 17, 18)

Leite e sangue jorram do corpo feminino. O primeiro branco, puro como símbolo da maternidade, da força de mulher que sustenta, que acolhe o filho. O segundo, vermelho vivo, resultado da violência, da marca indelével do estupro que fere não apenas o corpo, mas identidade feminina.

A mulher negra reassume, assim, na cenografia do estupro, o caráter de um corpo destinado ao prazer masculino, cuja vontade se sobrepõe ao direito dela sobre si e seu desejo. A luxúria que 
essa mulher personifica no imaginário masculino e o pecado que o discurso religioso condena orientam as ações do marido e dessacralizam o ato sexual que não gera vida, mas é fruto da violência.

Com o ato violento, desconstrói-se também o posicionamento que o discurso religioso católico legitima: o sexo na relação conjugal como forma de participação no plano divino de povoação da Terra. O estupro anulou o caráter procriativo e deu vazão à luxuria e à violência.

O mesmo corpo que proporcionou prazer, segurança, desejo transfigurou-se no corpo concreto do agressor que machuca, dilacera e toca aquilo que a mulher tem de mais íntimo: sua identidade. A fala de Aramides e a cenografia do estupro encerram-se com o abandono do agressor que culpa a vítima por não ter compartilhado o momento de prazer fruto do ato de violência.

\section{Considerações finais}

Do que foi visto no decorrer do capítulo, é possível verificar que a $\mathrm{AD}$ forneceu-nos categorias que permitiram verificar como as relações de poder, os estereótipos negativos e o discurso religioso atravessam o discurso literário. Pode-se destacar o lugar que a mulher negra ocupa na sociedade e como o tratamento que recebe está fundamentado em posicionamentos não assumidos que margeiam o dizer e orientam condutas.

Foi possível ainda dar maior cientificidade ao texto literário Aramides Florença, o qual tomado como um evento linguístico-discursivo, a partir da $\mathrm{AD}$, contribuiu na discussão acerca da violência doméstica, da posição subalterna que a mulher negra ocupa na sociedade brasileira, bem como a submissão e apagamento a que essa mulher está sujeita. 
A análise do discurso Aramides Florença possibilitou-nos verificar como a fusão entre enunciador e autor contribuem com o plano estético-literário de Evaristo sobre trazer a mulher negra para o debate acadêmico. Essa fusão auxiliou na apresentação de uma identidade da mulher negra que se desvincula dos estereótipos construídos na literatura canônica. Essa identidade enaltece a negritude e justifica a militância pelo direito de produzir uma literatura que saia das margens e consiga efetivamente chegar ao centro.

\section{Referências}

ALMEIDA, Silvio Luiz de. O que é racismo estrutural? Belo Horizonte (MG): Letramento, 2018.

DUARTE, Eduardo de Assis. O negro na literatura brasileira, Navegações, v.6, n.2, p.146-153, jul./dez, 2013

DUARTE, Constância Lima; DUARTE, Eduardo de Assis; ALEXANDRE, Marcos Antônio (orgs.). Falas do outro: literatura, gênero, etnicidade. Belo Horizonte, Nandyala; NEIA, 2010.

CATECISMO DA IGREJA CATÓLICA. Libreria Editrice Vaticana, Città del Vaticano, 1997.

CUTI. Literatura negro-brasileira. São Paulo: Selo Negro Edições, 2010.

EVARISTO, Conceição. Insubmissas lágrimas das mulheres. 2. ed. Rio de Janeiro: Malê, 2016.

EVARISTO, Conceição. Literatura negra: uma poética de nossa afro-brasilidade. Scripta, v. 13, n. 25, p. 17-31, 2009. Disponível em: Acesso em 18 ago. 2021

MAINGUENEAU, Dominique. A Análise do Discurso e suas fronteiras. Matraga, Rio de Janeiro, v.14, n.20, 2007a, pp. 13-37.

MAINGUENEAU, Dominique. Discurso e Análise do Discurso. Tradução Sírio Possenti. São Paulo: Parábola, 2015. 
140 A SUBMISSÃo DA MULHER NEGRA E A VIOLÊNCIA DOMÉSTICA

MAINGUENEAU, Dominique. Discurso Literário. São Paulo: Contexto, 2018.

RIBEIRO, Djamila. O que é lugar de fala? Belo Horizonte (MG): Letramento; Justificando, 2017. 